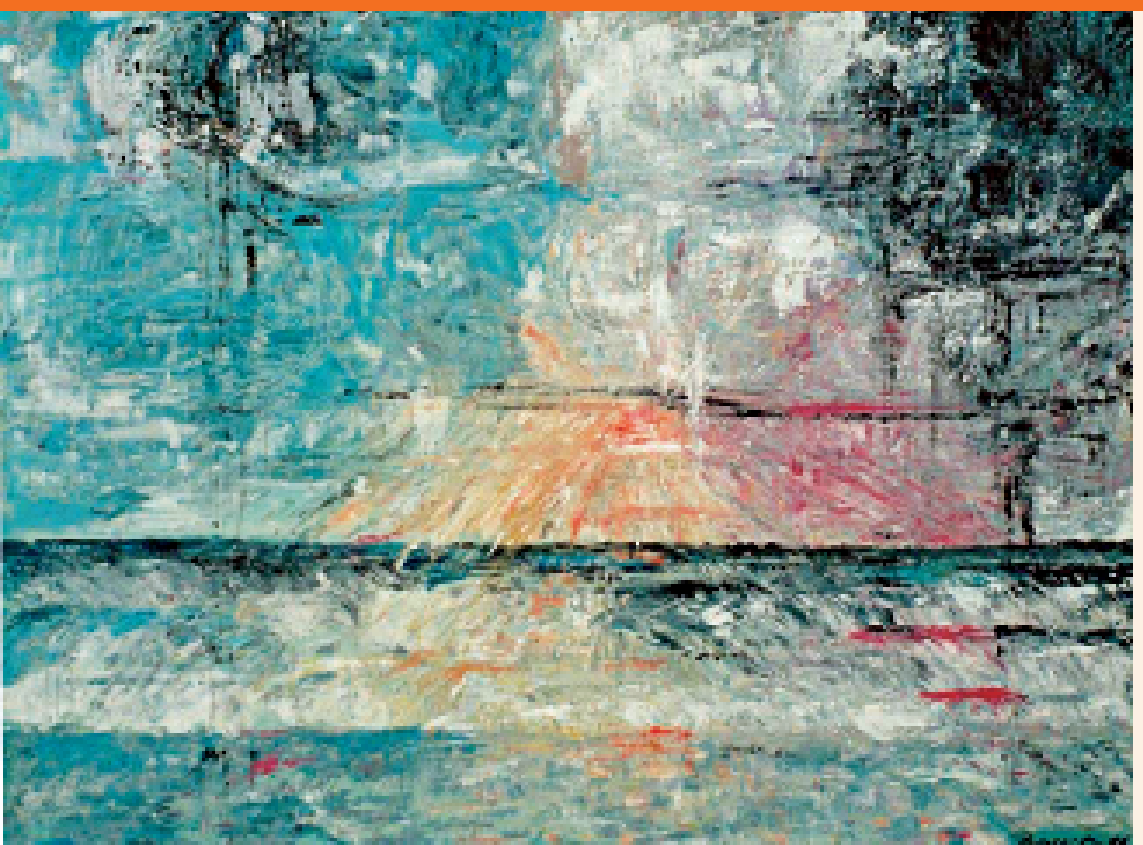

Harriet Keller: Sylt II Expression, Acryl.

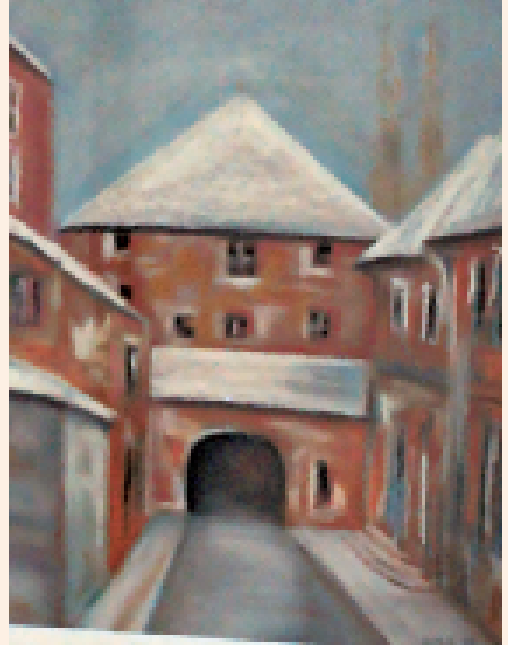

Sonja Saravanja: Zagreb, Pastellkreide.

\title{
Vor Bildern Frieden und Ruhe finden...
}

\section{David Künzler}

Korrespondenz:

Dr. med. David Künzler Jakob Zürrer Strasse 35 CH-8915 Hausen am Albis

www.aerzte-kunst.ch
Erneut können Ärztinnen und Ärzte im Rahmen der Kunstausstellung der Schweizer Ärzte/Salon des Médecins Suisses ihre Werke zum Verkauf anbieten, diesmal in der Galerie der Klinik Barmelweid (ob Aarau). Seit Jahren führt dort Herr Walo Steiner in schönen, hellen Räumen in einem Flügel der Klinik eine Galerie, die oft benützt und gut besucht ist.

An der Vernissage am 1. Juli 2006 kam bei einer kleinen Einführung zur Sprache, dass Bilder komponiert werden müssen. Durch Herrn Jerry Rojas (Arzt in Zürich) wurde der Akt mit Eigenkompositionen auf der Gitarre umrahmt, und David Künzler zitierte einerseits seinen künstlerischen Lehrer, dass man «Bilder komponieren» müsse und ergänzte diese Aussage mit Zitaten von Matisse: «...meine Farbverbindungen müssen zu einem Farbakkord führen, zu einer Harmonie, ähnlich der musikalischen...», und: «...ich möchte, dass der müde und gebrochene Mensch vor meinen Bildern Frieden und Ruhe findet...». Man vergesse nicht: Auch vor sogenannt abstrakten, ungegenständlichen Bildern kann dies sehr gut geschehen. Auch der bekannte Maler Caspar David Friedrich hatte den Wunsch, «...Musik und Malerei zu einem Gesamtkunstwerk zu verbinden...» (Neue Zürcher Zeitung vom 3./4. Juni 2006.

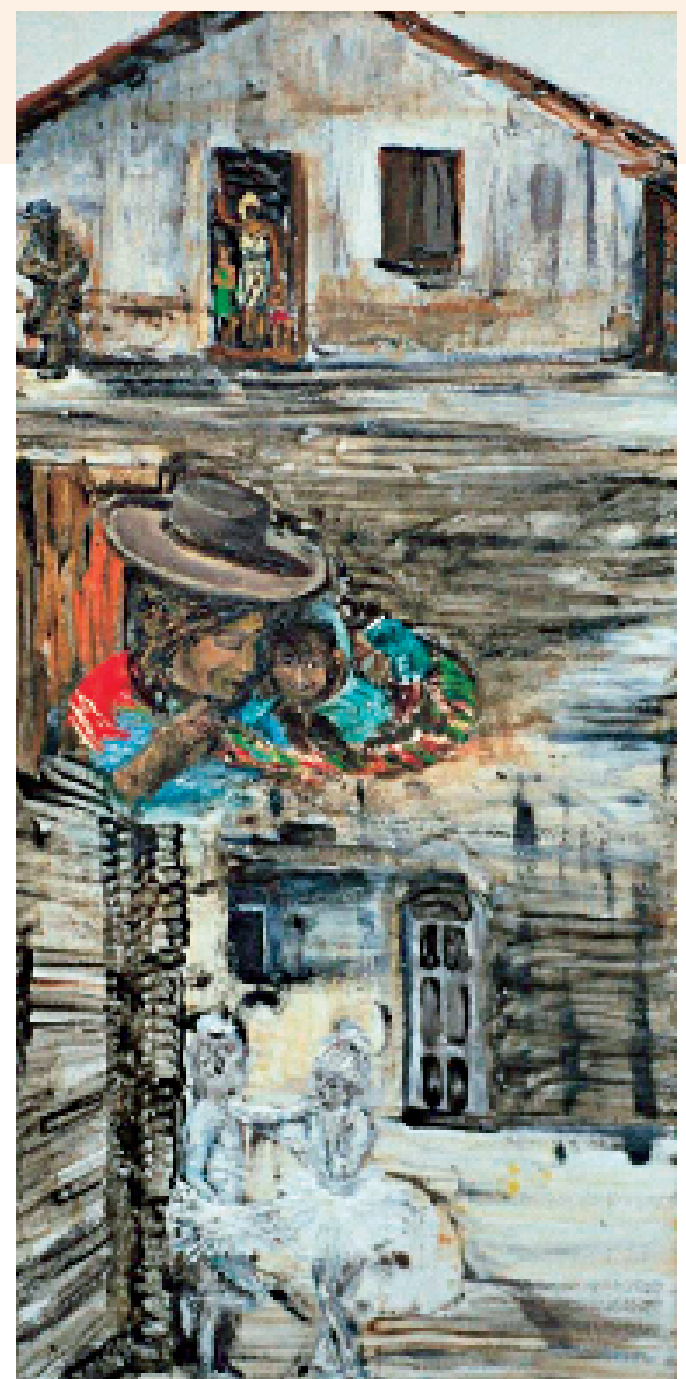

Rolf Weber: Mexico, Acryl. 


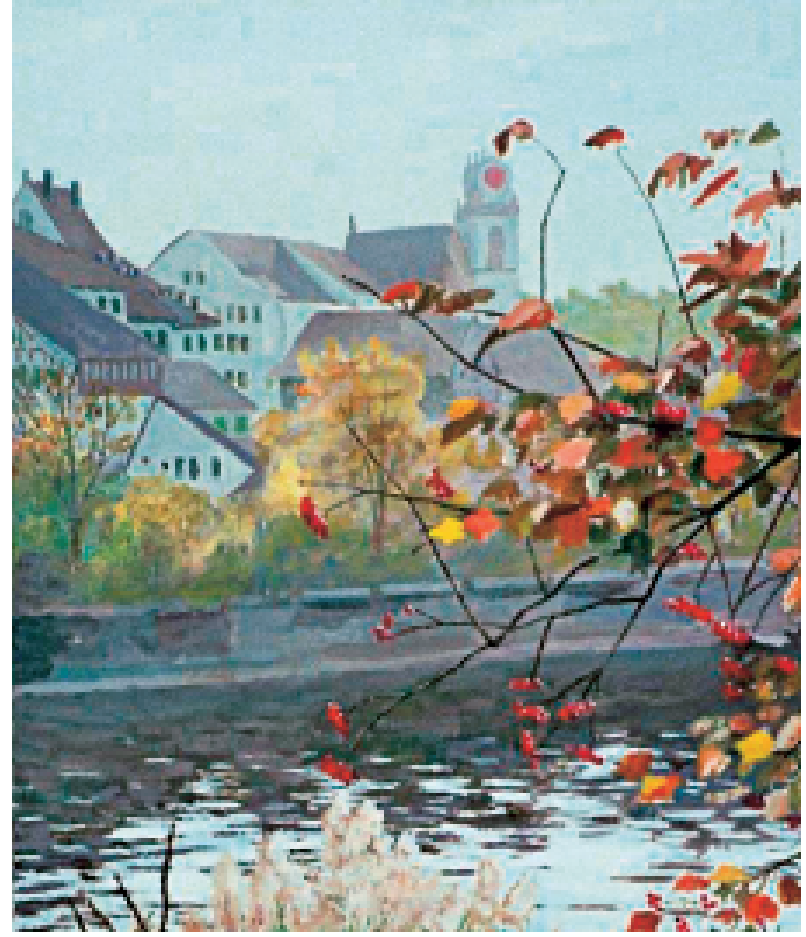

Kob Wintsch: Aarau im Herbst, Acryl.

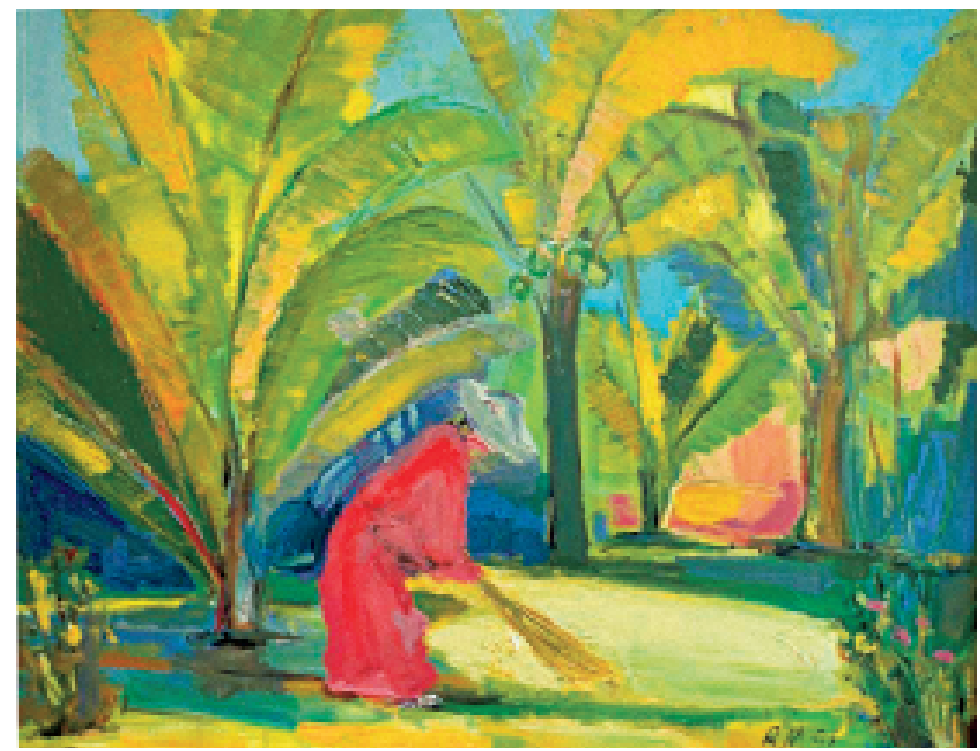

Rodolphe Meyer: Sous les palmes aux Seychelles.
So hatten die Besucher denn gut Gelegenheit, die sehr verschiedenen und sehr verschieden «zusammengestellten», eben komponierten Bilder in sich aufzunehmen, begleitet von den Klängen von Herrn Rojas.

Die folgenden Abbildungen zeigen eine Auswahl aus den 80 variantenreichen Bildern, die von 11 Kolleginnen und Kollegen geschaffen wurden. Wie immer bei Verkaufsausstellungen geben wir einen Teil der Einnahmen einem Hilfswerk, diesmal einem Projekt für sauberes Wasser in Entwicklungsländern, genannt SODIS.

Die Ausstellung dauert noch bis 27. August und ist von 10-20 Uhr täglich geöffnet. Die Klinik ist praktisch zu erreichen vom Bahnhof Aarau aus mit dem Bus, der alle Stunden fährt und ein Besuch kann auch mit Spaziergängen und Wanderungen verbunden werden.

Besuchen Sie uns auch auf der Internetseite www.aerzte-kunst.ch.

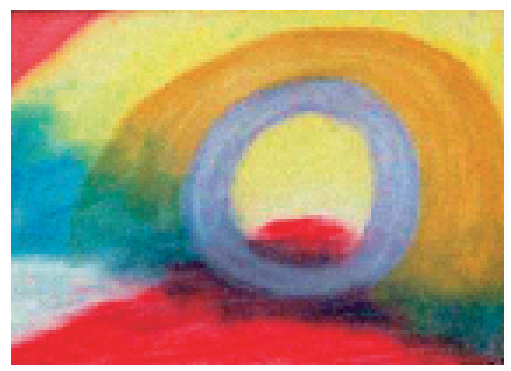

David Künzler: Ring, Pastellkreide. 